(c) American Dairy Science Association, 2005.

\title{
Trends and Seasonality of Reproductive Performance in Florida and Georgia Dairy Herds from 1976 to 2002*
}

\author{
A. de Vries $^{1}$ and C. A. Risco ${ }^{2}$ \\ ${ }^{1}$ Department of Animal Sciences, and \\ ${ }^{2}$ Department of Large Animal Clinical Sciences, University of Florida, Gainesville 32611
}

\begin{abstract}
Trends in reproductive performance from 1976 to 2002 were studied for dairy farms located in Florida and Georgia using 2,897,517 Dairy Herd Improvement Association lactation records of Holstein cows. One-half of the 1552 herds in the final edited records had measures for at least $8 \mathrm{yr}$. Measures of reproductive performance changed significantly over time. Days to first service increased from a low of $84 \mathrm{~d}$ in 1983 to $104 \mathrm{~d}$ in 2001. Cows that calved during spring had 9.2 (1983) to 33.2 (1999) more days to first service than cows that calved during fall. Annual pregnancy rates (PR) for 71 to $364 \mathrm{~d}$ since last calving (DSC; $\mathrm{PR}_{71-364}$ ) decreased from $21.6 \%$ in 1977 to 1979 , to $12 \%$ in 2000 to 2002. The greatest $\mathrm{PR}_{71-364}$ was observed during winter and the lowest during summer (15.8 vs. $5.6 \%$ in 2002 , respectively). The absolute difference between $\mathrm{PR}_{71-364}$ during winter and summer remained similar over time at 11 percentage units. Pregnancy rates in the early stages since calving (71 to $133 \mathrm{~d}$ ) showed greater decreases over time than PR in the later stages since calving. From 1998 to 2002, PR in the later stages since calving (134 to $364 \mathrm{~d}$ ) was on average $11.5 \%$. Pregnancy rate from 71 to $133 \mathrm{DSC}$ remained greater (13.4\%). In the winter, the decrease in $\mathrm{PR}_{71-364}$ was primarily due to a large decrease in $\mathrm{PR}_{71-91}$. Average days to conception increased from a low of 121 in 1982 to a high of 167 in 1998. The average difference between cows that calved during spring and fall increased from $22 \mathrm{~d}$ in 1976 to $47.5 \mathrm{~d}$ in 1986, but remained constant at $39.1 \mathrm{~d}$ from 1985. Average calving interval increased from $399 \mathrm{~d}$ in 1976 to 429 d in 2000 . Average days dry between 1976 and 2001 remained similar at $69 \mathrm{~d}$. Days to culling of nonpregnant cows after 182 DSC increased from 341 in 1983 to 415 in 1998. Season of calving had no clear
\end{abstract}

Received January 14, 2005.

Accepted May 16, 2005.

Corresponding author: Albert de Vries; e-mail: devries@animal. ufl.edu.

*This research was supported by the Florida Agricultural Experiment Station and USDA-IFAFS grant 2001-52101-11318 and approved for publication as Journal Series No. R-10695. association with average days to culling. The last milk yield recorded less than 1 mo before culling of nonpregnant cows after 182 DSC decreased by DSC to approximately 1 yr since calving, after which it remained constant at an average of $12.3 \mathrm{~kg} / \mathrm{d}$. The last known milk yield of cows culled during spring was $1.6 \mathrm{~kg} / \mathrm{d}$ greater than those culled during fall. This difference did not significantly change over time. Increases in actual 305$\mathrm{d}$ herd milk production were associated with increased days to first service, days to conception, and calving interval, but also with increased $\mathrm{PR}_{71-364}$. Herd size did not have a clear association with reproductive efficiency.

(Key words: seasonality, pregnancy rate, reproduction, trend)

Abbreviation key: DSC = days since last calving, $\mathbf{P R}=$ pregnancy rate, $\mathbf{V W P}=$ voluntary waiting period .

\section{INTRODUCTION}

Several studies have reported declines in reproductive performance in dairy herds since the 1950s in the United States. Washburn et al. (2002) found an increase in days to first service from 84 to 100 between 1985 and 1999 in Holstein herds in 10 Southeastern states that were on continuous DHIA test during that period. During that same period, estrus-detection rate decreased from about 51 to $42 \%$. Days open increased from about 126 in 1976 to 169 in 1999. Days open included actual days to conception for pregnant cows, plus estimated days to conception for nonpregnant cows. Services per conception, including all services in all cows, also increased, from 1.9 in 1976 to 3.0 in 1999. Similar increases in services per conception were reported by Lucy (2001) as well as increases in calving interval from $13.4 \mathrm{mo}$ in 1970 to $14.8 \mathrm{mo}$ in 1999 in herds on continuous DHIA test that were processed by Dairy Records Management Systems (Raleigh, NC). First-service conception rates in New York dairy herds decreased from approximately $65 \%$ in 1951 to $40 \%$ in 1996 (Butler, 1998). In Kentucky, conception rates in herds enrolled in DHIA decreased from 62\% in 1972 to $34 \%$ in 1996 (Silvia, 1998). In Ohio, days to first service 
increased from 90 to 94 and days to conception increased from 136 to 151 in herds enrolled in DHIA between 1992 and 1998 (Rajala-Schultz and Frazer, 2003). The review by Lucy (2001) cited additional studies that documented a reduction in reproductive performance outside the United States. The decline in reproductive performance coincided with increases in herd sizes and milk production per cow (Lucy, 2001; Stevenson, 2001; Washburn et al., 2002; Rajala-Schultz and Frazer, 2003). A decline in reproductive performance is a concern because reduced reproductive performance is associated with reduced profitability (Hady et al., 1994; Pecsok et al., 1994; Plaizier et al., 1998; Risco et al., 1998).

Trends in days open and services per conception were reported for 9 herds located in Florida and 47 herds located in Georgia that were constantly tested by DHIA from 1976 through 1999 (Washburn et al., 2002). Both measures are affected by the culling policy of nonpregnant cows. Furthermore, such small samples may be less than representative of the reproductive performance in the dairy industry in Florida and Georgia in a given year.

A preferred measure of reproductive performance is pregnancy rate (PR), which is sometimes estimated as the product of estrus-detection rate and conception rate (Ferguson and Galligan, 1999; Stevenson, 2001). Pregnancy rate represents the proportion of cows that become pregnant each estrous cycle. Cows that failed to conceive and have been culled are included in the PR calculation. Therefore, PR is less affected by reproductive culling policies. Pregnancy rates can be calculated for various stages since calving. Trends in PR over time have not been previously described.

Significant seasonality in reproductive performance exists in the southeastern United States (Al-Katanani et al., 1999; Oseni et al., 2003). In Spain (López-Gatius, 2003), significant decreases in cyclicity and conception rates were reported during warmer summer months, compared with cooler winter months in 4 herds between 1991 and 2000. The studies in the United States that were previously mentioned reported trends in annual means of reproductive measures, but did not document trends in seasonality.

The primary objective of this study was to describe the trends in reproductive measures from 1976 to 2002 for DHIA herds tested in Florida and Georgia. The primary measures of interest were trends over time and seasonality in PR. Other measures of interest were days to first service, days to conception, days dry, calving interval, calving rate, days between calving (DSC), and culling of cows that failed to become pregnant, and changes in the amount of milk recorded at the last test day before culling. A secondary objective was to report associations of herd size and 305-d milk production with trends in reproductive measures.

\section{MATERIALS AND METHODS}

\section{Lactation Records}

Results obtained in this study were calculated from DHIA lactation records. Lactation records containing reproductive and milk production data of Holstein cows in DHIA herds located in Florida and Georgia were obtained from Dairy Records Management Systems in Raleigh, NC. Few records were available before 1976 or after 2002; therefore, the period of interest was 1976 through 2002. Records that began before 1976 were included if they contained data for the period of interest.

Each record started with a calving date. Cows without a first-lactation calving date were excluded. A lactation record was considered completed when a subsequent calving date was recorded for the same cow. Otherwise, the record was considered not completed. For each record, the dates of the following events (if any) were determined: calving, first service, conception, last DHIA test before culling, culling, dry-off, and censoring.

Records that did not end in a subsequent calving date or a cull date were considered censored at the last known event date. The last known event date was the last known calving date, breeding date, test date, or dry-off date, whichever was later. However, events after 1095 DSC were ignored for censored cows and the last known event date was set to $1095 \mathrm{~d}$ after the calving date. Furthermore, dates after December 31, 2002, were ignored and the last known event date was then set to December 31, 2002. For each record, the number of cowdays was calculated as the number of days between the calving date and the last known event date.

First-service dates could only be determined for records that were not completed, because records for completed lactations of the same cow did not contain any breeding dates. Days to first service $>365$ were not included.

Conception dates for completed records were calculated by adding the reported days open (number of days when the cow was not pregnant) to the calving date that started the record. However, if the resulting gestation was less than $220 \mathrm{~d}$ or more than $300 \mathrm{~d}$, then conception dates were calculated as the next calving date minus $280 \mathrm{~d}$. Conception dates that resulted in abortion could not be determined. Thus, only the conception date that resulted in a subsequent calving was used. If the record was not completed and a due date was reported, then the conception date was calculated as $280 \mathrm{~d}$ before the due date. If a cow did not have a reported due date, but was reported pregnant, then her last breeding date was used as the conception date. 
Using the calculated conception date, days to conception were calculated as the number of days between calving and conception.

For the PR calculations, cows were assumed to become eligible for breeding on $\mathrm{d} 71$ after calving. This assumption of a voluntary waiting period (VWP) of 70 $\mathrm{d}$ was made because the observed days to first breeding were frequently shorter than the reported VWP on DHIA Herd Summary reports that were available for several herds. Despite some early breedings, many cows might not have been eligible for breeding if a very short VWP was assumed. Therefore, it was assumed that all cows were eligible for breeding using the longer 70-d VWP. For records with a conception date, the maximum number of eligible days was calculated as conception date minus calving date minus 70 . For records without a conception date, the maximum number of eligible days was calculated as the last known event date minus calving date minus 70 .

The actual 305-d milk yield was part of each DHIA lactation record. Milk yield at 70 DSC was calculated from the linear interpolation between the milk yield on the DHIA test day before $d 70$ and the DHIA test day just after d 70. Time between DHIA tests was typically $30 \mathrm{~d}$.

\section{Herd Measures}

The final data contained 2,897,517 lactation records. From these edited lactation records, various measures were calculated per herd per period. Periods were either calendar years or seasons. Default year and season were based on the month of calving. Seasons were defined in the following way: winter (January-March), spring (April-June), summer (July-September), and fall (October-December). Thus, each herd had annual measures for no more than $27 \mathrm{yr}$ (1976 through 2002) or seasonal measures for no more than 108 seasons (winter 1976 through fall 2002).

Herd measures of primary interest included the following: average days to first service, average days to conception, $\mathrm{PR}$, average days dry, average calving interval, calving rate, average days to culling of nonpregnant cows after 182 DSC (6 mo), and average milk yield at last DHIA test before culling of nonpregnant cows after 182 DSC.

Herd measures were calculated as follows. Average days to first service and average days to conception were calculated using all records that had a first service or conception date.

Percentage PR per herd per period was calculated as follows: (cumulative number of conceptions in the period) / (cumulative number of eligible days in the period / 21) $\times 100$. Number of conceptions and number of eligible days were calculated for 5 stages after calving: 71 to 133,134 to 196,197 to 259,260 to 364 , and 71 to 364 DSC. Therefore, various PR were calculated, depending on the stage after calving. For example, the $\mathrm{PR}$ for 71 to $133 \mathrm{DSC}$ was referred to as $\mathrm{PR}_{71-133}$. To limit the effect of unreliable PR, PR for periods with less than 210 cumulative eligible days were excluded and PR greater than $60 \%$ were set at $60 \%$. Season and year for the PR calculations were based on the months that cows were eligible to become pregnant, and not on the season of calving. Averages for days dry and calving intervals were calculated for completed lactations. Percentage calving rate was calculated as follows: (number of calvings in the period $\times 365$ ) / (number of cow days in the period) $\times 100$. This definition of calving rate was calculated as a comprehensive measure of reproductive efficiency. Cows that were not pregnant and culled after 182 DSC were assumed culled at least in part for failure to get pregnant. Average days between calving and culling dates were calculated, as well as the average milk yield at the last DHIA test within $31 \mathrm{~d}$ of the culling date. In this case, year was defined as the year culling took place.

Also of interest was the association between the reproductive herd measures and milk production and herd size. To this effect, average 305-d milk yields per herd per yr were grouped in 3 categories: 4000 to 5999, 6000 to 7999 , and 8000 to $9999 \mathrm{~kg}$. These 3 categories were referred to as low, average, and high-producing herds, respectively. Average milk yields $<4000$ or $>9999$ $\mathrm{kg}$ were ignored in this analysis. Similarly, average numbers of cows per herd per year were grouped: 20 to 99,100 to 499 , and 500 to 1499 cows. These 3 categories were referred to as small, medium, and large-size herds, respectively. Herds having $<20$ or $>1499$ cows were ignored in this analysis. These categories were based on an equally distributed number of observations per category.

Per herd and period, lactations were classified into 1 of 5 quintiles based on milk yield at 70 DSC. Periods were defined based on the season and year at 70 DSC.

Herds also were grouped into 1 of 3 regions based on geographic location: Georgia, North Florida (counties north of the line from Tampa to Orlando), and South Florida (counties south of the line from Tampa to Orlando).

\section{Statistical Analyses}

To estimate annual least squares means, mixed models were fit with year as a fixed effect. Herd measures per period were treated as repeated measures within herd. This specification can appropriately handle missing and unbalanced data (Littell et al., 1996). A com- 


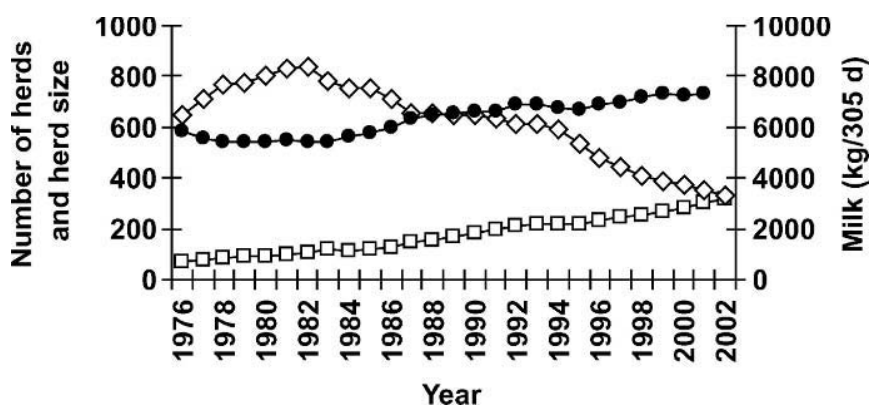

Figure 1. Number of herds $(\diamond)$, average annual number of cows per herd $(\square)$, and average annual 305-d milk production $(\mathbf{k g})$ from 1976 to 2002 in the DHIA data set.

pound symmetry covariance structure between the repeated records within herds was specified for all herd measures because the Akaike information criterion suggested a similar or better fit to the data than the default (no covariance), first-order autoregressive, and unstructured covariance structures (Littell et al., 1998). This repeated measures specification with a compound symmetry covariance structure is identical to fitting herd as a random effect (Littell et al., 1998).

To estimate least squares means per season per year, mixed models were fit with year, season, and their interaction as fixed effects, and herd as a random effect. Other model specifications were similar for the annual models. Linear trends of the herd measures over time were estimated with the same model specifications, except with year as a covariate (Littell et al., 1996). Linear effects of 305-d milk production per 305-d milk yield category and herd size per herd size category on herd measures were estimated with mixed models that included year and year $\times$ year as covariates with other specifications as stated before.

Significance was declared when $P<0.05$. Data editing and statistical analyses were performed using SAS version 8.2 (SAS Institute, Inc., Cary, NC).

\section{RESULTS}

\section{Number of Herds, Herd Size, and Milk Production}

The final data set contained herd measures from 1552 herds. Of these, 72 herds $(5.0 \%)$ had only 1 yr of measures, whereas 98 herds (5.9\%) had measures for all 27 yr. Half of all herds had measures for at least $8 \mathrm{yr}$.

Average number of cows per herd increased from 67 to 318 during the $27 \mathrm{yr}$ of the study (Figure 1). Number of herds tested was largest in 1982 (838 herds) and decreased to 329 herds in 2002. In 1993, an average of 131,798 cows was present in the DHIA data; the largest number of all $27 \mathrm{yr}$. Average 305-d milk production was

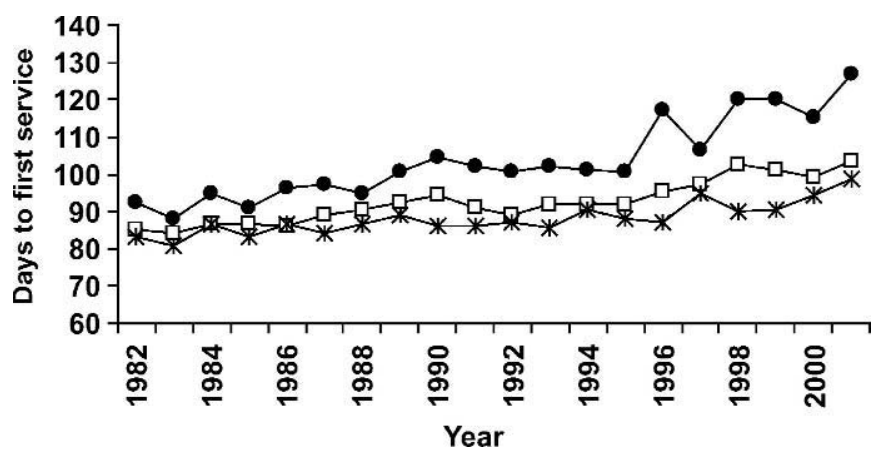

Figure 2. Least squares means of days to first service from 1982 to 2001 for calvings during spring ( ), fall (*), and average for the year $(\square)$. Average standard error is $1.7 \mathrm{~d}$ for the average year, $2.3 \mathrm{~d}$ for spring, and $2.2 \mathrm{~d}$ for fall.

smallest in 1978 at $5388 \mathrm{~kg}$ and the largest in 2001 at $7295 \mathrm{~kg}$.

\section{Days to First Service}

Breeding dates were not available in records before 1982. Average days to first breeding for calvings in 2002 were excluded because of potential bias introduced by including data after 2002. Figure 2 shows that average days to first service increased from $84.3 \pm 1.5$ in 1983 to $103.7 \pm 1.9$ in 2001 . This increase $(P<0.001)$ was on average $0.87 \pm 0.07 \mathrm{~d}$ per $\mathrm{yr}$, but varied over time. The average increase $(P \leq 0.001)$ from 1982 to 1988 was $0.87 \pm 0.27 \mathrm{~d}$ per yr. From 1989 to 1995 , days to first service numerically decreased on average $0.18 \pm 0.28$ $\mathrm{d}$ per yr, but this decrease did not differ from zero. The increase $(P<0.01)$ from 1996 to 2001 was $1.29 \pm 0.43$ d per yr.

Cows that calved during spring had the most days to first service, whereas cows that calved during fall had the fewest (Figure 2). Difference in days to first service between cows calving during spring and fall was $9.2 \pm 2.7 \mathrm{~d}$ in 1983 , but increased $(P<0.001)$ to $33.2 \pm$ $3.3 \mathrm{~d}$ in 1999. On average, this difference increased $(P$ $<0.001$ ) by $1.02 \pm 0.12 \mathrm{~d}$ per yr. Cows that calved during spring also had the greatest increase $(P<0.001)$ in days to first service since 1982, compared with cows that calved during other seasons.

An increase in the 305-d milk production was associated with greater days to first service at lower levels of milk production only. For low-producing herds, an increase of $1000 \mathrm{~kg}$ was associated with an increase $(P$ $<0.001)$ of $4.8 \pm 1.4 \mathrm{~d}$ to first service. Average-producing herds had numerically $0.9 \pm 0.9$ more days to first service per $1000 \mathrm{~kg}$, whereas high-producing herds had a numerical increase of $1.8 \pm 2.2 \mathrm{~d}$ per $1000 \mathrm{~kg}$ of greater production, but these changes did not differ from zero. 


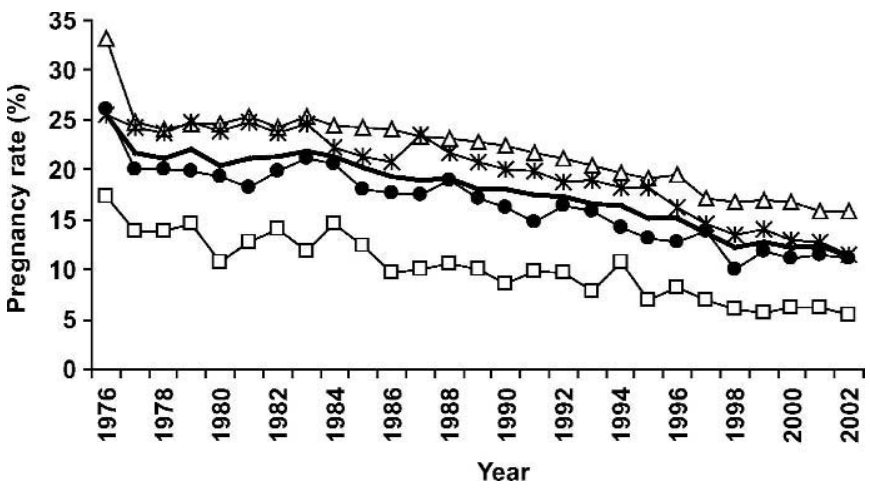

Figure 3. Least squares means of pregnancy rates for 71 to 364 $\mathrm{d}$ since calving $\left(\mathrm{PR}_{71-364}\right)$ per season: winter $(\triangle)$, spring $(\bullet)$, summer $(\square)$, fall (*), and the average for the year (-). Average standard error is 0.4 percentage points.

Small herds had an increase $(P<0.01)$ of $8.5 \pm 3.0 \mathrm{~d}$ to first service per 100 cows. In contrast, larger herd size was associated negatively with days to first service. Medium-size herds reported a decrease $(P<0.001)$ in days to first service of $3.8 \pm 0.6$ and large herds reported a decrease $(P<0.001)$ of $2.5 \pm 0.5 \mathrm{~d}$ per 100 cows increase.

\section{Pregnancy Rates}

Figure 3 shows the gradual decrease $(P<0.001)$ in $\mathrm{PR}_{71-364}$ during the $27 \mathrm{yr}$ examined. Average annual $\mathrm{PR}_{71-364}$ from 1977 to 1979 was $21.6 \%$ and decreased $(P<0.001)$ to an average of $12 \%$ from 2000 to 2002 . This is a decrease $(P<0.001)$ of on average $0.45 \pm 0.01$ percentage points per yr since 1976 .

Seasonal effects on $\mathrm{PR}_{71-364}$ were large. The greatest $\mathrm{PR}_{71-364}$ was observed during winter and the smallest during summer, whereas $\mathrm{PR}_{71-364}$ during fall was greater $(P<0.001)$ than that during spring (Figure 3$)$. The absolute difference between $\mathrm{PR}_{71-364}$ during winter and summer remained similar over time (average of 11 percentage points). Between 1989 and 1995, however, the difference between $\mathrm{PR}_{71-364}$ in the winter and summer decreased $(P<0.001)$ by $0.49 \pm 0.09$ percentage points per yr, but from 1996 to 2002, this difference remained constant at 9.6 percentage points. Because both $\mathrm{PR}_{71-364}$ during winter and summer decreased over time, the ratio of summer $\mathrm{PR}_{71-364}$ to winter $\mathrm{PR}_{71-364}$ decreased $(P<0.001)$ from $56 \%$ in the 1970 s to $35 \%$ in 2002. Thus, the relative seasonality increased over time, but not the absolute seasonality. Since 1983, the decrease in $\mathrm{PR}_{71-364}$ was the largest during fall (from 25 to $12 \%$ ) and the smallest during summer (from 12 to $6 \%$ ).

An increase in the 305-d milk production was associated with an increase in $\mathrm{PR}_{71-364}$. For low-producing

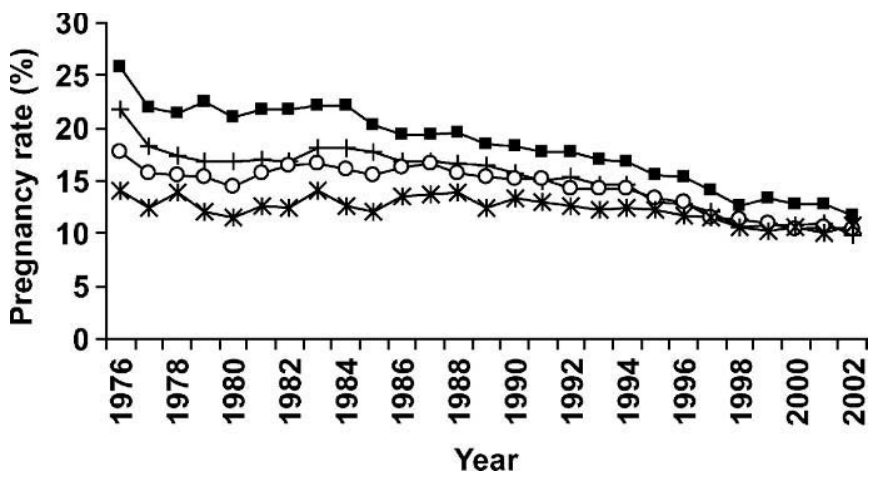

Figure 4. Least squares means of annual pregnancy rates for 4 stages since calving: 71 to $133 \mathrm{~d}\left(\mathrm{PR}_{71-133} ; \mathbf{\square}\right), 134$ to $196 \mathrm{~d}\left(\mathrm{PR}_{134-}\right.$ $\left.{ }_{196} ;+\right), 197$ to $259 \mathrm{~d}\left(\mathrm{PR}_{197-259} ; \mathrm{O}\right)$, and 260 to $364 \mathrm{~d}\left(\mathrm{PR}_{260-364 ;} ;{ }^{*}\right)$. Average standard errors are $0.4\left(\mathrm{PR}_{71-133}\right), 0.4\left(\mathrm{PR}_{134-196}\right), 0.5\left(\mathrm{PR}_{197-}\right.$ $259)$, and $0.6\left(\mathrm{PR}_{260-364}\right)$ percentage points.

herds, an increase of $1000 \mathrm{~kg}$ of milk was associated with an increase $(P<0.001)$ of $1.07 \pm 0.19$ percentage points in $\mathrm{PR}_{71-364}$. Average-producing herds showed an increase $(P<0.001)$ of $0.60 \pm 0.16$ percentage points in $\mathrm{PR}_{71-364}$ per $1000 \mathrm{~kg}$ of milk. High-producing herds tended $(P=0.063)$ to have an increase of $0.72 \pm 0.39$ percentage points in $\mathrm{PR}_{71-364}$ per $1000 \mathrm{~kg}$ of milk produced.

In small herds, an increase in herd size per 100 cows was associated with a decrease $(P<0.001)$ of $4.62 \pm$ 0.39 percentage points in $\mathrm{PR}_{71-364}$. In medium-size herds, the decrease $(P<0.01)$ was $0.29 \pm 0.10$ percentage points, whereas in large herds, no association was detected between increasing herd size and $\mathrm{PR}_{71-364}$.

Further, no difference was detected in linear trends for $\mathrm{PR}_{71-364}$ over time between first and greater lactation numbers.

Stage since calving. Figure 4 shows the trends in annual PR calculated for 4 stages since calving (71 to 133,134 to 196,197 to 259,260 to 364 DSC). Pregnancy rates in the early stages since calving showed greater decreases $(P<0.001)$ over time than PR in later stages since calving. From 1998 to 2002, PR in the later stages since calving (134 to $364 \mathrm{~d}$ ) were on average $11.5 \pm 0.2 \%$ and not significantly different. Pregnancy rates in the early stage since calving ( 71 to $133 \mathrm{~d}$ ) were greater (13.4 $\pm 0.2 \% ; P<0.001$ )

The trends in $\mathrm{PR}_{71-133}$ and $\mathrm{PR}_{134-197}$ during winter and summer are shown in Figure 5. During winter, the decrease in $\mathrm{PR}_{71-133}$ was greater $(P<0.001)$ than the decrease in $\mathrm{PR}_{134-197}$, which resulted in a difference of more than 8 percentage points in the early 1980s to a difference of less than 2 percentage points from 1998 to 2002. The large decrease in $\mathrm{PR}_{71-133}$ during winter was primarily due to a decrease $(P<0.001)$ in $\mathrm{PR}_{71-91}$, whereas the decrease in $\mathrm{PR}_{91-112}$ was much smaller and 


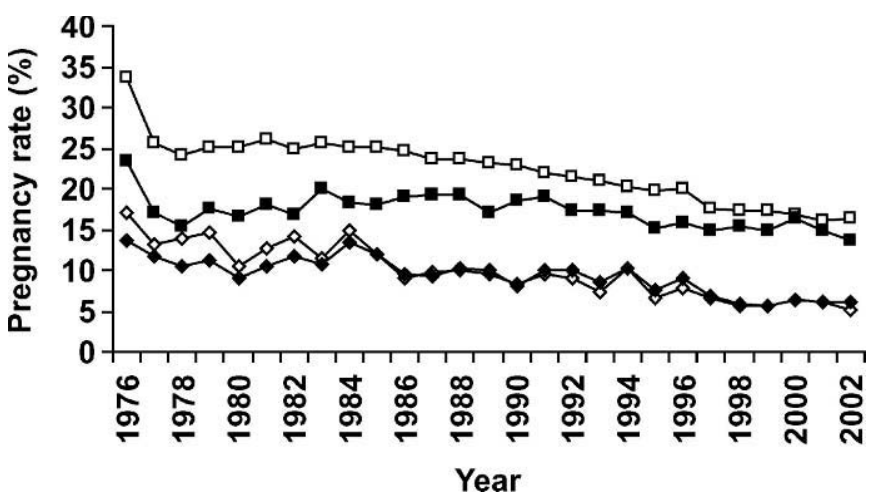

Figure 5. Least squares means of pregnancy rates for 2 stages since calving during winter and summer: 71 to $133 \mathrm{~d}$ since calving $\left[\mathrm{PR}_{71-133}\right.$; winter $(\square)$, summer $\left.(\diamond)\right]$, and 134 to $197 \mathrm{~d}$ since calving $\left[\mathrm{PR}_{134-197}\right.$; winter $(\mathbf{\square})$, summer $\left.(\bullet)\right]$. Average standard errors are 0.4 $\left(\mathrm{PR}_{71-133}\right)$ and $0.6\left(\mathrm{PR}_{134-197}\right)$ percentage points.

similar to the decrease $(P<0.001)$ in $\mathrm{PR}_{134-197}$ (not shown). During summer, the decrease in $\mathrm{PR}_{71-133}$ was numerically greater $(P>0.05)$ than the decrease in $\mathrm{PR}_{134-197}$. The trends in the seasonality of $\mathrm{PR}$ for later stages since calving (197 to 259 and 260 to 364 DSC) were similar to those for $\mathrm{PR}_{134-197}$.

Differences between $\mathrm{PR}_{71-133}$ during winter and summer were greater $(P<0.001)$ than the differences between $\mathrm{PR}_{134-197}$ during winter and summer during all $27 \mathrm{yr}$ of the study. The difference between $\mathrm{PR}_{71-133}$ during winter and summer decreased $(P<0.001)$ over time, whereas the difference between $\mathrm{PR}_{134-197}$ in the winter and summer increased $(P<0.01)$ over time.

Milk yield at 70 DSC. Estimated milk yields at 70 DSC were available from 1985 to 2002. Within herds, $\mathrm{PR}_{71-133}$ for lactations in the largest quintile for milk yields were on average 1.6 percentage points less than for lactations in the smallest quintile. This difference typically decreased $(P<0.05)$ from 1987 to 1997 , but increased $(P<0.05)$ from 1998 to 2002 (Figure 6).

Region. Of the 1552 herds in this study, 1004 were located in Georgia, 388 were located in North Florida, and 160 in South Florida. The decrease $(P<0.001)$ in $\mathrm{PR}_{71-364}$ was not the same for all regions (Figure 7). The linear decrease in $\mathrm{PR}_{71-364}$ was largest for Georgia and smallest for South Florida, with all 3 linear decreases being different from each other $(P<0.05)$. The $\mathrm{PR}_{71-364}$ from 1998 to 2002, however, were not different. The trends for $\mathrm{PR}_{71-364}$ per season were similar to the annual trends.

\section{Days to Conception}

Trends and seasonality for days to conception were similar to those for days to first service. Average days

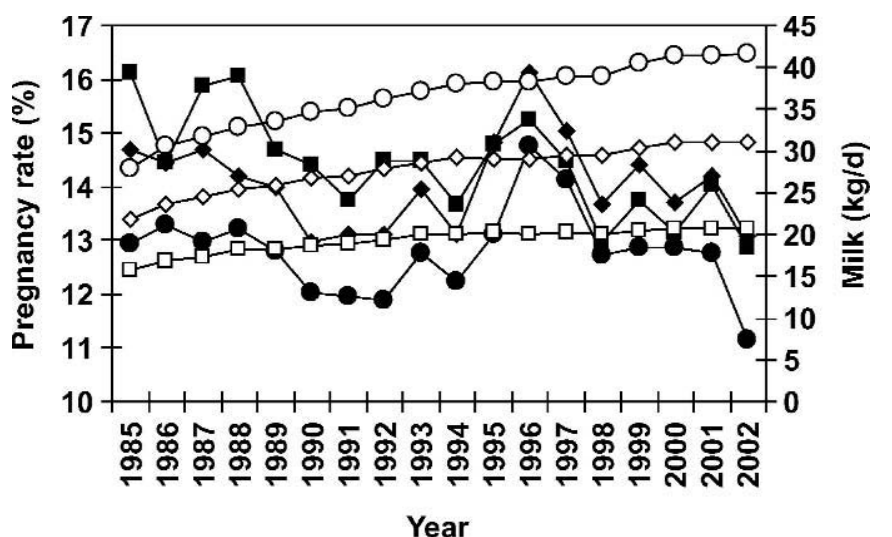

Figure 6. Least squares means of pregnancy rates for 71 to 133 d since calving $\left(\mathrm{PR}_{71-133}\right)$ by first $(\square)$, third $(\diamond)$, and fifth $(\bigcirc)$ quintile of 70-d milk yield and corresponding pregnancy rates [first (ם), third $(\diamond)$, and fifth $(\bullet)$ quintile]. Average standard errors for milk yield are $0.17,0.19$, and $0.25 \mathrm{~kg} / \mathrm{d}$; and average standard errors of pregnancy rates are $0.46,0.44$, and 0.40 percentage points for first, third, and fifth quintiles, respectively.

to conception increased $(P<0.001)$ from $120.9 \pm 1.5$ in 1982 to $167.3 \pm 2.0$ in 1998 , but decreased $(P<0.001)$ after 1998 (Figure 8). On average, the increase was 1.35 $\pm 0.05 \mathrm{~d}$ per yr for the $26 \mathrm{yr}$ considered.

Spring-calving cows had the largest $(P<0.001)$ average days to conception, whereas fall-calving cows had the fewest $(P<0.001)$ days to conception. The average difference increased $(P<0.001)$ from $22.0 \pm 2.4 \mathrm{~d}$ in 1976 to $47.5 \pm 2.3 \mathrm{~d}$ in 1986 , but remained fairly constant at $39.1 \pm 2.5 \mathrm{~d}$ since 1985 . Cows that calved during winter had the largest $(P<0.001)$ increases in days to conception since 1983. Cows that calved during summer had the smallest $(P<0.001)$ increases.

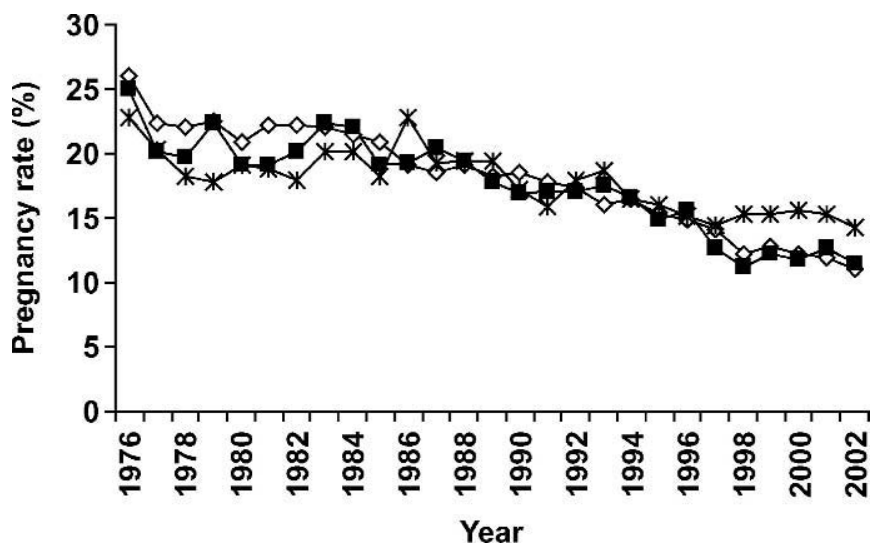

Figure 7. Least squares means of pregnancy rates for 71 to 364 d since calving $\left(\mathrm{PR}_{71-364}\right)$ per region: Georgia $(\diamond)$, North Florida $(\mathbf{\square})$, South Florida (*). Average standard errors are 0.4 (Georgia), 0.7 (North Florida), and 1.2 (South Florida) percentage points. 


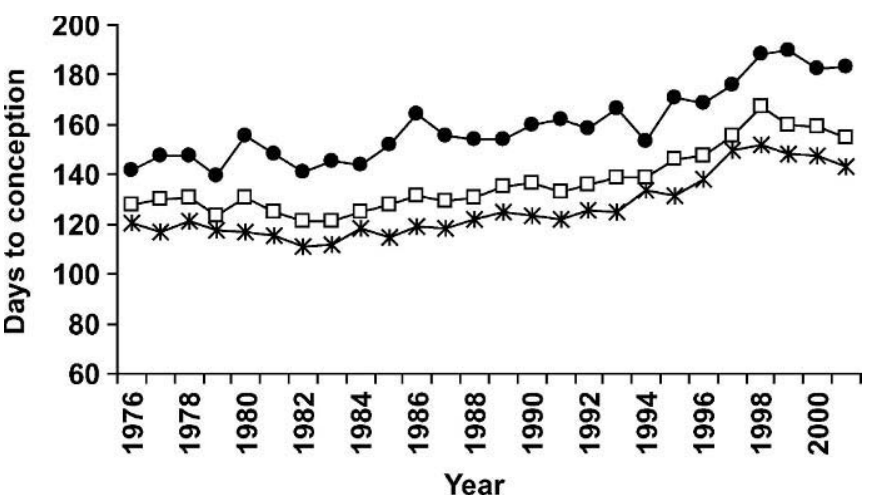

Figure 8. Least squares means of days to conception from 1976 to 2001 for calvings during spring $(\mathbf{0})$, fall (*), and average for the year $(\square)$. Average standard error is $1.7 \mathrm{~d}$ for the average year and $2.1 \mathrm{~d}$ for spring and fall.

More $(P<0.001) 305$-d milk production was associated with increased days to conception. Low-producing herds had $8.1 \pm 1.0$ more $(P<0.001)$ days to conception per $1000 \mathrm{~kg}$ of milk. This increase $(8.2 \pm 0.8 \mathrm{~d})$ was similar for average-producing herds, whereas the increase was $8.4 \pm 1.9 \mathrm{~d}$ per $1000 \mathrm{~kg}$ for high-producing herds.

Days to conception increased $(P<0.001)$ with herd size in smaller herds. Small herds had $9.8 \pm 1.9$ more days per 100 cows, whereas the increase was $1.8 \pm 0.5$ $\mathrm{d}$ per 100 cows for medium-size herds. Increases in herd size tended $(P=0.057)$ to be associated with fewer days to conception for large herds.

\section{Days Dry, Calving Interval, and Calving Rate}

Days dry. Average days dry between 1976 and 2001 was constant at $68.8 \pm 0.7 \mathrm{~d}$. A linear increase $(P<$ 0.001 ) was small; only $0.08 \pm 0.02 \mathrm{~d}$ per yr. Average days dry, however, decreased by $1.9 \pm 0.4(P<0.001)$ and $1.5 \pm 0.9(P<0.001)$ per $1000 \mathrm{~kg}$ of greater $305-\mathrm{d}$ milk production in low- and average-producing herds, respectively. An increase in herd size was associated with more days dry in small herds $(4.5 \pm 0.9 \mathrm{~d}$ per 100 cows; $P<0.001)$ and medium-size herds $(0.6 \pm 0.2 \mathrm{~d}$ per 100 cows; $P<0.01$ ), but no significant association was detected with herd size in large herds.

Calving interval. Average calving interval increased $(P<0.001) 1.1 \pm 0.1 \mathrm{~d}$ per yr from $399 \pm 2 \mathrm{~d}$ (13.1 mo) in 1976 to $429 \pm 2 \mathrm{~d}$ (14.1 mo) in 2000 (Figure 9). Cows that calved during spring had the longest $(P$ $<0.001$ ) calving interval. Seasonal trends were similar to those for days to conception. Greater 305-d milk production was associated with an average increase $(P<$ 0.001 ) in calving interval of $9.5 \pm 1.2 \mathrm{~d}$ per $1000 \mathrm{~kg}$. Increases in herd size in small- and large-size herds

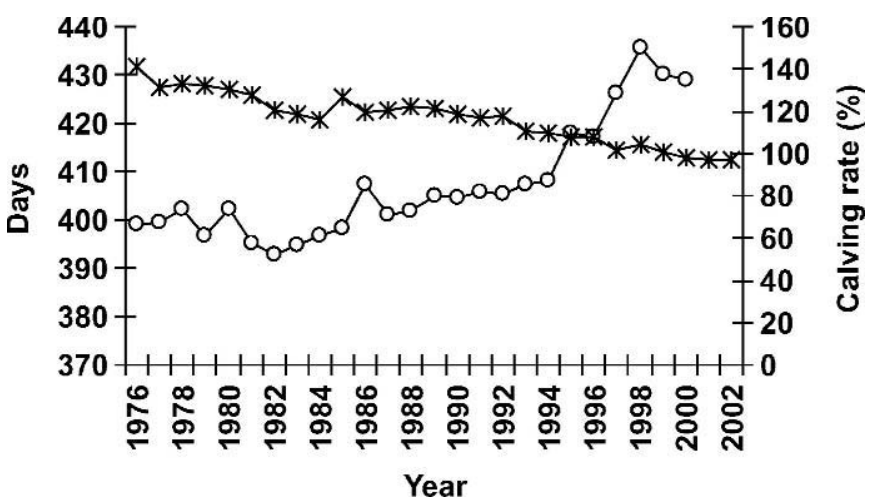

Figure 9. Least squares means of calving interval $(\bigcirc)$ from 1976 to 2001 and calving rate $(*)$ from 1976 to 2002 . Average standard error is $1.6 \mathrm{~d}$ for calving interval and 2.2 percentage points for calving rate.

were associated with decreases in calving interval (4.7 $\pm 2 \mathrm{~d} ; P<0.05)$ and $1.4 \pm 0.5 \mathrm{~d}(P<0.01)$ per 100 cows, respectively. Herd sizes in medium-size herds were not associated with changes in calving interval.

Calving rate. Calving rate decreased from approximately $134 \pm 2 \%$ in the 1970 s to $97 \pm 2 \%$ after 2000 , an average decrease $(P<0.001)$ of $1.44 \pm 0.06$ percentage points per yr. Milk yield was not significantly associated with changes in calving rate in average- or high-producing herds, but calving rate decreased $(P<0.001)$ by 3.9 \pm 1.2 percentage points per $1000 \mathrm{~kg}$ in low-producing herds. Increases in herd size were associated with decreases $(P<0.001)$ in calving rate, but the association was smaller in larger herds.

\section{Days to Culling of Nonpregnant Cows and Last Known Milk Yield Before Culling}

Days to culling. Figure 10 shows the trends in days to culling of nonpregnant cows after 182 DSC. From

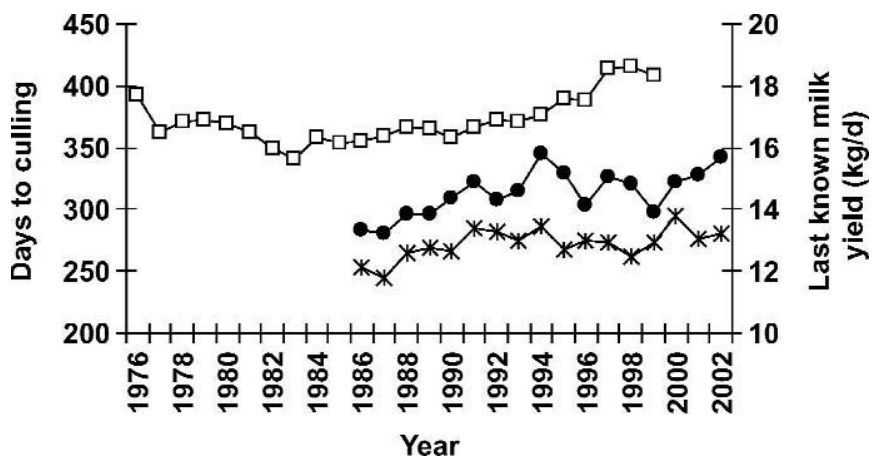

Figure 10. Least squares means of days to culling of cows not pregnant after $182 \mathrm{~d}$ since calving $(\square)$, and last known milk yield within $31 \mathrm{~d}$ of culling of cows not pregnant after $182 \mathrm{~d}$ since calving, for cows culled during spring $(\bullet)$ and fall $(*)$. Average standard error for days to culling is $5 \mathrm{~d}$. Average standard error for last known milk yield is $0.3 \mathrm{~kg} / \mathrm{d}$. 
1976 to 1983 , a decline $(P<0.001)$ from $392 \pm 6 \mathrm{~d}$ to $341 \pm 5 \mathrm{~d}$ occurred, but from 1983 to 2002, days to culling increased $(P<0.001)$ by $3.4 \pm 0.3 \mathrm{~d}$ per yr to a maximum of $415 \pm 6 \mathrm{~d}$ in 1998. Season of calving had no clear association with average days to culling.

More 305-d milk production was associated with greater days to culling, but the association was weaker in the higher producing herds. In low-producing herds, days to culling increased $(P<0.001)$ by $28 \pm 4 \mathrm{~d}$ per $1000 \mathrm{~kg}$. In average-producing herds, this increase $(P$ $<0.001$ ) was $25 \pm 3 \mathrm{~d}$ per $1000 \mathrm{~kg}$, and in high-producing herds the increase $(P<0.05)$ was $21 \pm 9 \mathrm{~d}$ per $1000 \mathrm{~kg}$. No significant association was detected between herd size and days to culling.

Last known milk yield. The last known DHIA milk yield within $31 \mathrm{~d}$ of culling of nonpregnant cows after 182 DSC increased $(P<0.001)$ by $0.22 \pm 0.02 \mathrm{~kg} / \mathrm{d}$ per yr to $14.5 \pm 0.2 \mathrm{~kg} / \mathrm{d}$ in 1994 . After 1994, the last known milk yield before culling remained constant at $14.1 \pm$ $0.2 \mathrm{~kg} / \mathrm{d}$.

The last known milk yield of cows culled during spring was $1.6 \pm 0.4 \mathrm{~kg}$ greater than those culled during fall (Figure 10). This difference did not change over time. Average last known milk yields for cows culled during winter and summer were in between those of spring and fall.

Herds that produced more milk per cow culled nonpregnant cows at increasingly greater milk yields. Lowproducing herds had a $0.57 \pm 0.22 \mathrm{~kg}$ increase $(P<0.01)$ per $1000 \mathrm{~kg}$ of milk, whereas high-producing herds were associated with a $1.02 \pm 0.27 \mathrm{~kg}$ increase $(P<0.001)$ per $1000 \mathrm{~kg}$ of milk when nonpregnant cows were culled. Herd size was not clearly associated with last milk yield before the culling of nonpregnant cows. Medium-size herds had a decrease $(P<0.001)$ of $0.37 \pm$ $0.09 \mathrm{~kg}$ of milk per 100 cows. No significant association was detected for small and large herds.

Figure 11 shows that the last known milk yield before culling of nonpregnant cows after $182 \mathrm{DSC}$ decreased $(P$ $<0.001$ ) by DSC until approximately $1 \mathrm{yr}$ since calving. After 1 yr since calving, the last known milk yield remained constant averaging $12.3 \pm 0.2 \mathrm{~kg} / \mathrm{d}$.

\section{DISCUSSION}

The objective of this study was to document trends in reproductive performance in herds located in Florida and Georgia between 1976 and 2002. All herds that had DHIA records at least some time between 1976 and 2002 were included in this study to obtain results that were, as much as possible, representative of the entire dairy industry in these 2 states. Few herds had records for all $27 \mathrm{yr}$.

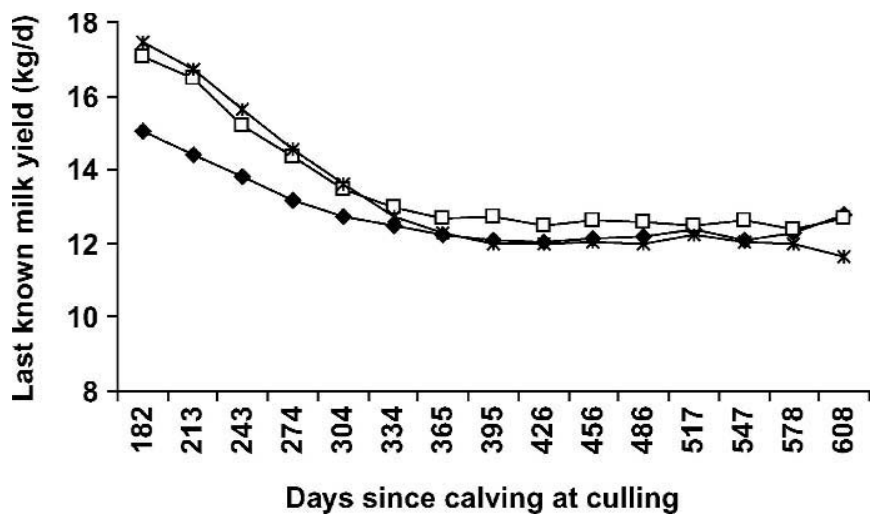

Figure 11. Least squares means of last known milk yield within $31 \mathrm{~d}$ of culling of cows that were nonpregnant at the time of culling. Only culling that took place after $182 \mathrm{~d}$ since calving was considered. The following 3 periods were considered: 1986 to $1990(\$), 1991$ to $1995(\square)$, and 1996 to 1999 (*). Average standard error is $0.2 \mathrm{~kg} / \mathrm{d}$. The days since calving were grouped in months.

In general, reproductive performance in these herds has decreased over time, whereas herd size and milk production have increased. These results are in agreement with previous studies that documented trends in annual reproductive performance in the Southeastern United States over time (Stevenson, 2001; Washburn et al., 2002). Some results for the last few years of this study may be biased because year and season were based on date of calving. For example, days to first service, days to conception, and calving interval were calculated for cows with a breeding date, pregnancy date, or next calving date. Therefore, cows that had these events recorded late after calving were excluded in the calculations for the final years of the study.

Average annual days to first service in this study (Figure 2) increased approximately $20 \mathrm{~d}$ from 1982 to 2002 , similar to a previous report (Washburn et al., 2002). Days to first service, however, could only be determined in lactations that were not completed. Therefore, average days to first service in this study may be a biased measure of the average time to first service of all cows after calving. Bias may partially explain the fewer days to first service in the 1980s. Despite recommended shorter VWP of 40 to $50 \mathrm{~d}$ in the $1980 \mathrm{~s}$, average intervals to first service derived from DHIA data were consistently in the 85-d range. The availability of Lutalyse after 1979 may have helped reduced days to first service in some herds.

A constant VWP for all cows in a herd could not be reliably determined for most herds. The VWP varies from 40 to $70 \mathrm{~d}$ on most farms (Stevenson, 2001). If a short VWP is assumed $(<70 \mathrm{~d})$, then many eligible days would be calculated for cows that in practice were not 
yet eligible. This would significantly underestimate the true PR. If a longer VWP is assumed, then some eligible days in practice would not be calculated and some pregnancies that were established before $70 \mathrm{~d}$ would be ignored. It was assumed that PR estimates using a longer VWP were less biased. Therefore, cows were determined to be first eligible for breeding on $71 \mathrm{DSC}$, based on the distribution of first services for a sample of herds. Cows that became pregnant before $\mathrm{d} 71$ were ignored for the PR calculations, but not for the calculation of the other reproductive measures.

Pregnancy rates calculated in this study may be underestimated because in completed lactations, and in herds that use natural service sires, only the conception that resulted in calving was available. Conceptions earlier since calving that resulted in abortion after pregnancy diagnosis were ignored. During the time between conception and abortion, the cow is not eligible for breeding and those days should be excluded from the PR calculation if known. Consequently, average days to conception also may be overestimated.

The decline in $\mathrm{PR}_{71-364}$ over time was large and was similar for all seasons (Figure 3). The large decrease from 1976 to 1977 may be an unknown bias in the available data. In contrast to these findings, LópezGatius (2003) found a decrease in conception rates during summer, but not during winter. Pregnancy rate is the result of both estrus-detection rate and conception rate. Washburn et al. (2002) found decreases in estrusdetection rate from approximately 51 to $42 \%$ and decreases in conception rate from approximately 47 to $34 \%$ from 1985 to 1999 . The estimated changes in PR calculated from those data (from 24 to $14 \%$ ) are similar to those found in this study. From Figure 4, it was clear that the PR during early stages since calving was greater than in later stages since calving, but also that decrease was the most profound during early stages since calving. Furthermore, this decrease during early stages since calving was greater during winter than during summer.

Early stages of lactation during winter are the time when cows produce the most milk in Florida and Georgia (DeLorenzo et al., 1992; de Vries, 2004). Increases in 305-d milk production were associated in this study with increases in days to first service, days to conception, and calving interval. The apparent correlation between greater milk production and greatest loss in fertility may be partially explained by the antagonistic genetic correlation between milk production and fertility (Dematawewa and Berger, 1998; Hansen, 2000). However, the phenotypic correlation between milk production and fertility is weak and less clear (Lucy, 2001). The association between milk yield at 70 DSC and subsequent $\mathrm{PR}_{71-133}$ in the present study was also not strong. Greater risk factors for decreased fertility are incidence of disease (Loeffler et al., 1999; Gröhn and Rajala-Schultz, 2000). Thus, possible increases in disease incidence may explain some of the decreases in fertility over time. Lucy (2001) discussed many other biological factors that may partially explain the decrease in reproductive efficiency. The effect of herd size on reproductive performance was not clear in the present study.

Deliberate changes in reproductive management also explain some of the decreases in reproductive performance measures. More dairy producers may have increased their VWP past $70 \mathrm{~d}$ because some studies showed increased conception rates after longer VWP (Britt, 1975) and some timed AI programs have suggested VWP past $70 \mathrm{~d}$ (Tenhagen et al., 2003). An actual VWP past $70 \mathrm{~d}$ reduces any PR that is calculated assuming a 70-d VWP. Increased VWP may explain why the decrease in $\mathrm{PR}_{71-91}$ was larger than the decrease in $\mathrm{PR}_{92-112}$.

Furthermore, some dairy producers deliberately do not breed cows during parts of the summer (Washburn et al., 2002; Oseni et al., 2003). Fertility of dairy cows is reduced under heat stress during hot summer months (Jordan, 2003) and delayed breeding may be economically advantageous (Gröhn and Rajala-Schultz, 2000; Arbel et al., 2001). When cow performance is seasonal, profit per stall is optimized if cows get pregnant during fall and winter months and cow replacement occurs primarily in the fall (de Vries, 2004). Both shorter VWP and deliberate delayed breeding reduce PR. Delayed breeding accounts partially for the observed lower PR during summer and more days to first service and days to conception of cows that calved during spring. On the other hand, improvements in environmental modification through cooling and shade (Bray et al., 1992) may have reduced heat stress during the study period. Seasonality in days to conception was similar to other observations (Oseni et al., 2003) for Florida and Georgia herds.

Declines in annual and seasonal $\mathrm{PR}_{71-364}$ were greater in Georgia and North Florida compared with South Florida (Figure 7). South Florida had the greatest $\mathrm{PR}_{71-364}$ in every season from 1998 to 2002. This result is in contrast with that of Al-Katanani et al. (1999), who reported that 90-d nonreturn rates during summer were least in South Florida compared with North Florida and South Georgia. Their sample size was only 17 herds, with 5 of those in South Florida.

Days to conception increased the most for cows that calved during winter, suggesting the greatest decrease in reproductive performance occurred during spring and summer. Days to conception is often called days open, but this is confusing because it is not clear if or 
how nonpregnant cows are included in the calculation. Different DHIA processing centers and studies may use different calculation rules (Rajala-Schultz and Frazer, 2003). Days to conception excludes nonpregnant cows. Washburn et al. (2002) used monthly days open records, which included actual days to conception for pregnant cows, but also estimates of days to conception for nonpregnant cows.

Average days dry remained nearly constant at $69 \mathrm{~d}$ from 1976 to 2002 , which is in agreement with national survey data (USDA, 2002). The recent interest in shorter dry periods (Grummer and Rastani, 2004) may change this in the near future.

Calving rate can be considered a comprehensive overall measure of reproductive performance because it is the result of VWP and PR, and includes days open of cows in their last lactation. Calving rate may be greater than $100 \%$ because the calving that starts the first lactation is included. Calving interval is also the result of VWP and PR, but excludes information from cows in their last lactation. Calving interval is therefore more affected by culling policy of nonpregnant cows than calving rate. Trends in calving interval follow those for days to conception plus the gestation length. Calving interval increased notably after 1990. An increase in calving interval of 0.5 mo in the 1990s was reported for Ohio herds (Rajala-Schultz and Frazer, 2003). Average calving interval in the Ohio study and our study were both near $14.1 \mathrm{mo}$ for the late 1990s.

Days to culling of cows that were nonpregnant after 182 DSC increased from 341 in 1983 to 415 in 1998 (Figure 10). Presumably, dairy producers keep breeding nonpregnant cows longer than they did in the past. This may be due to increases in milk production per cow because the milk yield at the last known DHIA test before culling remained fairly constant at $12.3 \mathrm{~kg}$ after $365 \mathrm{~d}$ since calving (Figure 11), which would typically be later in lactation when milk production increases. This milk yield may be near the perceived break-even yield in which milk sales equal variable costs of keeping the cow in the herd, which apparently has changed very little over time. Cows that left the herd before $365 \mathrm{~d}$ since calving may be culled for any number of reasons and therefore had greater milk yield at the last test day.

The observation that dairy producers give higherproducing cows more opportunity to get pregnant partially explains the increases in days open, days to conception, and calving interval over time. The economic benefits of giving higher-producing cows more time to get pregnant before they are subject to culling for failure to conceive may outweigh the perceived disadvantages of getting cows pregnant later after calving. Thus, decreases in these reproductive performance measures may be partially a result of good management. In- creased breeding period, however, does not explain the decreases in PR.

It is not clear why nonpregnant cows culled after 182 DSC during spring had a greater last milk yield than cows culled during fall. A greater voluntary replacement rate during fall compared with the spring is economically advantageous in Florida (DeLorenzo et al., 1992; de Vries, 2004), which implies that nonpregnant cows should be culled earlier after calving and at a greater rate of milk production to make space for replacement heifers.

\section{CONCLUSIONS}

In conclusion, all measures showed significant decreases in reproductive efficiency in Florida and Georgia dairy herds between 1976 and 2002. Declines in days to first service were the greatest for cows calving in spring, and declines in days to conception were the greatest for cows calving during winter, which suggest that the greatest decreases occurred during spring and summer. However, declines in PR were the greatest for the earlier stages since calving during winter. The absolute difference between $\mathrm{PR}_{71-364}$ in winter and summer has remained similar over time. Causes for the declines are likely to be both a reduction in cow fertility during winter, a longer VWP, a longer breeding period, and deliberately not breeding cows during summer. Amount of milk production at which nonpregnant cows were culled for reproductive reasons has remained steady since 1986, but the DSC when cows leave the herd for reproductive reasons has slightly increased.

\section{ACKNOWLEDGMENTS}

The authors appreciate the cooperation of Dairy Records Management Systems (Raleigh, NC) for providing the lactation records used in this study.

\section{REFERENCES}

Al-Katanani, Y. M., D. W. Webb, and P. J. Hansen. 1999. Factors affecting seasonal variation in 90-day nonreturn rate to first service in lactating Holstein cows in a hot climate. J. Dairy Sci. 82:2611-2616.

Arbel, R., Y. Bigun, E. Ezra, H. Sturman, and D. Hojman. 2001. The effect of extended calving intervals in high lactating cows on milk production and profitability. J. Dairy Sci. 84:600-608.

Bray, D. R., D. K. Beede, R. A. Bucklin, and G. L. Hahn. 1992 Cooling, shade, and sprinkling. Chapter 66 in Large Dairy Herd Management. American Dairy Science Association, Savoy, IL.

Britt, J. H. 1975. Early postpartum breeding in dairy cows. A review. J. Dairy Sci. 58:266-271.

Butler, W. R. 1998. Review: Effect of protein nutrition on ovarian and uterine physiology in dairy cattle. J. Dairy Sci. 81:2533-2539.

de Vries, A. 2004. Economic value of delayed replacement when cow performance is seasonal. J. Dairy Sci. 87:2947-2958.

DeLorenzo, M. A., T. H. Spreen, G. R. Bryan, D. K. Beede, and J. A. M. Vanarendonk. 1992. Optimizing model: Insemination, replace- 
ment, seasonal production, and cash flow. J. Dairy Sci. 75:885896.

Dematawewa, C. M., and P. J. Berger. 1998. Genetic and phenotypic parameters for 305-day yield, fertility, and survival in Holsteins. J. Dairy Sci. 81:2700-2709.

Ferguson, J. D., and D. T. Galligan. 1999. Veterinary Reproductive Programs. Pages 131-137 in Proc. 32nd Annu. Mtg. Amer. Assoc. Bovine Pract., Nashville, TN.

Gröhn, Y. T., and P. J. Rajala-Schultz. 2000. Epidemiology of reproductive performance in dairy cows. Anim. Reprod. Sci. 6061:605-614.

Grummer, R. R., and R. R. Rastani. 2004. Why reevalate dry period length? J. Dairy Sci. 87(E. Suppl.):E77-E85.

Hady, P. J., J. W. Lloyd, J. B. Kaneene, and A. L. Skidmore. 1994. Partial budget model for reproductive programs of dairy farm businesses. J. Dairy Sci. 77:482-491.

Hansen, L. B. 2000. Consequences of selection for milk yield from a geneticist's viewpoint. J. Dairy Sci. 83:1145-1150.

Jordan, E. R. 2003. Effects of heat stress on reproduction. J. Dairy Sci. 86(E. Suppl.):E104-E114.

Littell, R. C., P. R. Henry, and C. B. Ammerman. 1998. Statistical analysis of repeated measures data using SAS procedures. J. Anim. Sci. 76:1217-1231.

Littell, R. C., G. A. Milliken, W. W. Stroup, and R. D. Wolfinger. 1996. SAS System for Mixed Models. SAS Institute, Inc., Cary, NC.

Loeffler, S. H., M. J. de Vries, and Y. H. Schukken. 1999. The effects of time of disease occurrence, milk yield, and body condition on fertility of dairy cows. J. Dairy Sci. 82:2589-2604.

López-Gatius, F. 2003. Is fertility declining in dairy cattle? A retrospective study in northeastern Spain. Theriogenology 60:89-99.

Lucy, M. C. 2001. Reproductive loss in high-producing dairy cattle: Where will it end? J. Dairy Sci. 84:1277-1293.
Oseni, S., I. Misztal, S. Tsuruta, and R. Rekaya. 2003. Seasonality of days open in US Holsteins. J. Dairy Sci. 86:3718-3725.

Pecsok, S. R., M. L. McGilliard, and R. L. Nebel. 1994. Conception rates: Derivation and estimates for effects of estrus detection on cow profitability. J. Dairy Sci. 77:3008-3015.

Plaizier, J. C. B., G. J. King, J. C. M. Dekkers, and K. Lissemore. 1998. Modeling the relationship between reproductive performance and net-revenue in dairy herds. Agric. Sys. 56:305-322.

Rajala-Schultz, P. J., and G. S. Frazer. 2003. Reproductive performance in Ohio dairy herds in the 1990s. Anim. Reprod. Sci. 76:127-142.

Risco, C. A., F. Moreira, M. DeLorenzo, and W. W. Thatcher. 1998. Timed artificial insemination in dairy cattle. Part II. Compend. Contin. Educ. Prac. Vet. 20:1284-1289.

Silvia, W. J. 1998. Changes in reproductive performance of Holstein dairy cows in Kentucky from 1972 to 1996. J. Dairy Sci. 81(Suppl. 1):244. (Abstr.)

Stevenson, J. S. 2001. Reproductive management of dairy cows in high milk-producing herds. J. Dairy Sci. 84(E. Suppl.):E128E143.

Tenhagen, B.-A., C. Vogel, M. Drillich, G. Thiele, and W. Heuwieser. 2003. Influence of stage of lactation and milk production on conception rates after timed artificial insemination following Ovsynch. Theriogenology 60:1527-1537.

USDA. 2002. Part 1. Reference of Dairy Health and Management in the United States, 2002. USDA:APHIS:VS, CEAH, National Animal Health Monitoring System, Fort Collins, CO.

Washburn, S. P., W. J. Silvia, C. H. Brown, B. T. McDaniel, and A. J. McAllister. 2002. Trends in reproductive performance in Southeastern Holstein and Jersey DHI herds. J. Dairy Sci. 85:244-251. 